Case Study

\title{
Scheuermann's disease: non-surgical improvement in whole spine sagittal alignment in the treatment of a symptomatic patient using Chiropractic BioPhysics ${ }^{\circledR}$ technique
}

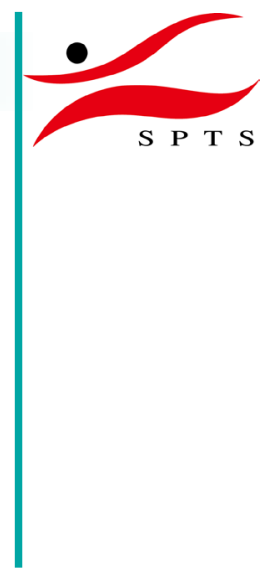

\author{
Niousha Navid Ehsani, MD²), Paul A. OAkley, DC, MSc ${ }^{1)^{*}}$, Deed E. Harrison, DC ${ }^{2)}$ \\ 1) Private Practice: Newmarket, ON, L3Y 8Y8, Canada \\ 2) CBP NonProfit, Inc., USA
}

\begin{abstract}
Purpose] To present the dramatic improvement of sagittal posture in a young male with Scheuermann's disease suffering from pain ailments as treated by Chiropractic BioPhysics ${ }^{\circledR}$ technique. [Participant and Methods] An 18 year old reported low back pain and headaches for several years. Full spine radiographic assessment revealed pronounced thoracic hyperkyphosis, anterior head translation, posterior thoracolumbar sagittal balance, and a reduced sacral base orientation. The patient was treated by Chiropractic BioPhysics methods incorporating mirror image ${ }^{\circledR}$ exercises, traction, as well as spinal manipulation. [Results] Assessment after 35 treatment sessions over 14-weeks revealed a dramatic improvement in postural parameters. The thoracic kyphosis reduced by $13^{\circ}$, and was accompanied by a reduction in forward head posture, reduction in posterior sagittal balance, and an increase in sacral base angle to normal. The low back pain and headaches were alleviated. [Conclusion] This case adds to the accumulating evidence demonstrating CBP methods offers an effective approach to reduce the burden of postural disorders including those with Scheuermann's disease. Since thoracic hyperkyphosis is a serious disorder, the routine comprehensive assessment via full-spine radiography is essential for the quantification of relevant postural parameters.

Key words: Scheuermann's disease, Thoracic hyperkyphosis, Low back pain
\end{abstract}

(This article was submitted May 27, 2018, and was accepted Aug. 14, 2019)

\section{INTRODUCTION}

The incidence of poor posture is inevitably high ${ }^{1,2)}$. Many studies have determined that postural misalignment or spinal subluxation is associated with pain and disability ${ }^{3-6)}$. Recently, in fact, it has been reported that those with poor posture had a significantly poorer quality of life scores as measured by the SF-36 questionnaire than those with various other well known diseases including self-reported arthritis, chronic lung disease, diabetes and congestive heart failure ${ }^{7)}$.

Scheuermann's disease (SD) is the development of exaggerated forward flexion of the thoracic spine (hyperkyphosis) that is also characterized by vertebral body wedging and endplate irregularities, diminished anterior vertebral body growth, Schmorl's nodes, narrowing of the intervertebral discs and premature disc degeneration ${ }^{8,9)}$. The disease is more prevalent in males, commencing usually in young adolescence, where the bones are in a continuous growing state. The symptoms are more prominent at flexion state, with mild relief with extension. Despite a lack of research regarding SD, its prevalence is estimated to range from $0.4-8 \%$ within the general population ${ }^{10}$. SD can lead to pulmonary and cardiovascular compromise due to the nature of affected anatomy and alignment of the spine. The main treatment for SD is physiotherapy exercise programs as well as spinal bracing, however, spinal bracing is generally considered more effective when performed early and

*Corresponding author. Paul A. Oakley (E-mail: docoakley.icc@gmail.com)

(C2019 The Society of Physical Therapy Science. Published by IPEC Inc.

(c) (1) $\odot$ This is an open-access article distributed under the terms of the Creative Commons Attribution Non-Commercial No Derivatives

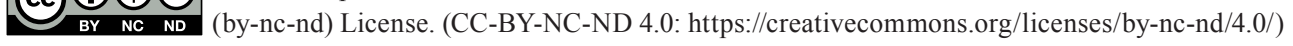


when the deformity has not progressed beyond $50^{\circ 9}$ ). Surgical treatment is rarely indicated, and only when the deformity is severe and progressing $\left(>75^{\circ}\right)$, accompanied by refractory pain, or with neurologic deficits ${ }^{9)}$.

Although there is evidence that Chiropractic BioPhysics ${ }^{\circledR}\left(\mathrm{CBP}^{\circledR}\right)$ technique can successfully reduce thoracic hyperkyphosis ${ }^{11)}$, there is no data specifically on patients with SD. We present a case showing the dramatic improvement of a severe thoracic hyperkyphosis postural subluxation in a young male with SD and associated low back and related pain complaints by incorporating CBP methods.

\section{PARTICIPANT AND METHODS}

On December 17, 2018, an 18-year-old male presented to the office with a chief complaint of lower back pain (LBP) radiating to his right hip and knee for the past 'several years'. He described his pain as constant, occurring daily and it was relieved with rest but aggravated with movement associated with routine activities such as sitting, standing or sleeping. The patient also reported suffering from 'horrible posture,' which he described as a hunched back and rigid. He also suffered from mild and occasional mid back pain, neck pain and headaches. The patient rated his LBP at $5 / 10$ on average $(0=$ no pain; $10=$ worst pain ever) and an $8 / 10$ at worst. The patient scored $42 \%$ on the Revised Oswestry Chronic Low Back Pain Disability Questionnaire (ODI) ${ }^{12)}$.

Initial physical examination revealed the patient reported pain upon palpation of the entire neck, mid and lower back area, and the muscles felt taught. Lumbar range of motion (ROM) was normal with the exception of being slightly limited and displayed crepitus while performing bilateral bending. Left and right lumbar rotation caused a pulling sensation. Cervical ROM was limited in all directions with the exception of flexion. All other orthopaedic tests were unremarkable.

The patient had a full spine and pelvis standing radiographic assessment which included antero-posterior (AP) and lateral cervical, thoracic, and lumbar images. The images were assessed and digitized using the PostureRay system (Trinity, FL, USA). Using this program, the lateral images were quantified via the Harrison posterior tangent (HPT) method, which measures the rotation between adjacent vertebra using the posterior tangents or lines contiguous with the posterior margins of each vertebral body ${ }^{13-15)}$. The AP views were evaluated via the modified Risser-Ferguson method, best fit lines from the estimated centre of mass of each vertebra ${ }^{16}$. These methods have very good reliability as does the assessment of standing posture $^{13-17)}$.

Several positive postural subluxation parameters were identified ${ }^{18)}$ including forward head translation as measured as the horizontal distance from the posterior superior $\mathrm{C} 2$ body corner to a line drawn from the posterior inferior $\mathrm{C} 7$ vertebral body corner $\left(36.8 \mathrm{~mm}\right.$ vs. 0 to $15 \mathrm{~mm}$ normal $\left.{ }^{19,20)}\right)$, posterior thoracic sagittal balance of the thoracolumbar spine as measured as the horizontal distance from the posterior inferior body corner of T12 and a line drawn vertically from the posterior inferior body corner of S1 (-17.8 $\mathrm{mm}$ vs. $0 \mathrm{~mm}$ ideal $\left.{ }^{21)}\right)$, and a T1-T12 absolute rotation angle (ARA) showing exaggerated thoracic hyperkyphosis $\left(69.3^{\circ}\right.$ vs. $44^{\circ}$ normal $\left.^{22}\right)$. The lateral lumbar view showed an L1-L5 ARA hyperlordosis $\left(-48.5^{\circ}\right.$ vs. -40 normal $\left.^{23,24)}\right)$ and a decreased sacral base angle $\left(31.5\right.$ vs. 40 normal $\left.{ }^{24)}\right)$. The C2-C7 ARA cervical lordosis was within normal limits $\left(-31.0^{\circ}\right.$ vs. -31 to $42^{\circ}$ normal $\left.{ }^{18,19,25)}\right)$. The AP images were unremarkable (i.e. vertical).

It is noted that an individual's pelvic morphology can dictate a unique and customization from 'ideal' lumbo-thoracic curves $^{26)}$, however, since the pelvic incidence for this patient was within normal limits $\left(58^{\circ}\right.$ vs. 43 to $62^{\circ}$ nor$\mathrm{mal}^{27)}$ ), the usual normative parameters were considered adequate for comparison ${ }^{22-24)}$. Further, due to the patient's age and thoracic hyperkyphosis, we evaluated the thoracic spine closely. It was noted that the patient had characteristic vertebral body wedging (upper thoracic spine) and endplate irregularities (lower thoracic spine) consistent with $\mathrm{SD}^{8,9)}$. We were the first to diagnosed the patient with SD.

Subsequent to initial assessment, the patient consented to treatment aimed at the correction of his poor sagittal posture. The patient started treatment integrating CBP methodology ${ }^{11,28,29)}$. This rehabilitation technique uses the mirror image ${ }^{\circledR}$ concept in the application of exercises, spinal adjustments, and traction. Although limited, there is evidence supporting the use of these methods in the attempt to reduce thoracic hyperkypho$\operatorname{sis}^{11)}$.

The patient performed thoracic extension traction (Fig. 1) in the supine position on a Denneroll traction table (Denneroll Spinal Orthotics, Wheeler Heights, NSW, Australia). The patient hung their head off the end

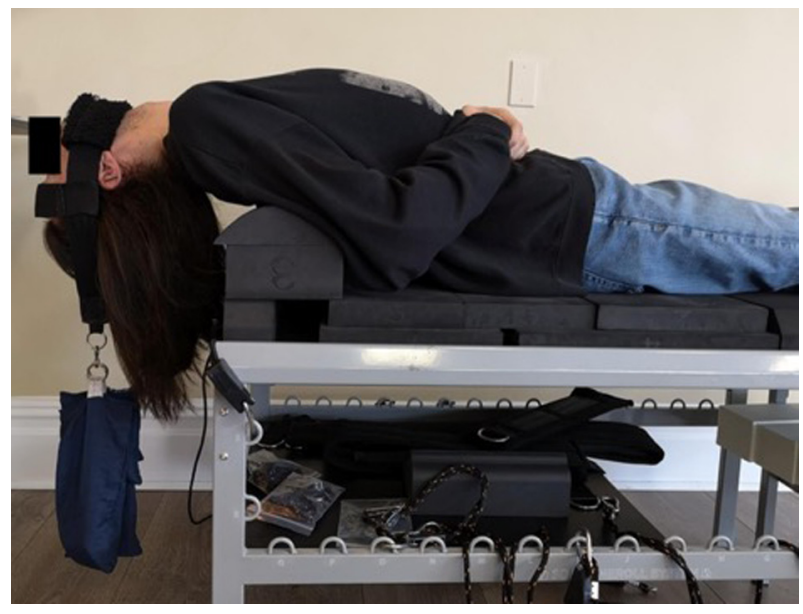

Fig. 1. Traction set-up. Patient lay supine with the head hanging off the end of the table with weight placed on a chin/ forehead strap. A convex block was placed at the peak of the hump created by the hyperkyphosis. Traction was performed for 10 minutes. 
of the table with a chin/forehead strap where weight was placed, initially none, and progressing to 8 pounds for a duration of 10 minutes. A convex block was placed at the apex of the patient's thoracic kyphosis to force a stretch as a reversal of the deformity (mirror image) as per CBP protocol.

The patient also performed four different back extension exercises. The first was the 'birddog,' where the patient was on all fours and alternated lifting the opposite leg and arm. The second exercise was a simple back extension while laying prone. The last two exercises were in the standing position. The third exercise was horizontal arm extensions with a resistance band, and the forth exercise consisted of arm 'W's', where the hands faced forward and slowly the arms were raised with the elbow bent to create a ' $\mathrm{W}$ ' and this was carried through until the arms were extended overhead, where the patient would then slowly reverse this position - all the while the shoulder blades were being pinched together. All exercises were done in a repeated fashion for 60 seconds each on the PowerPlate to intensify the exercises ${ }^{30)}$.

The patient also underwent full spine, spinal manipulative therapy each session. The patient was very compliant with the treatment plan that included three times per week from December 17, 2019 to April 3, 2019. The patient consented to the publication of these results including any pictures and radiographs.

\section{RESULTS}

Upon re-assessment after 35 treatments over 14 weeks, the patient reported to have total relief from LBP and headaches. He did report having occasional mid back pain, approximately 3-4 times per week when he sat for too long. All lumbar ROM was normal with no pain or discomfort, cervical ROM was improved but limited in bilateral bending. The ODI score was $0 \%$ for LBP. Repeat radiographic assessment showed significant improvement in several postural parameters (Figs. 2-5): forward head translation reduced to $18.4 \mathrm{~mm}\left(\mathrm{vs} .36 .8 \mathrm{~mm}\right.$ ), the thoracic hyperkyphosis reduced to $56.1^{\circ}$ (vs. $69.3^{\circ}$ ), the posterior thoracolumbar sagittal balance reduced to $-1.3 \mathrm{~mm}$ (vs. $-17.8 \mathrm{~mm}$ ), and the sacral base increased to $39.7^{\circ}\left(\mathrm{vs} .31 .5^{\circ}\right)$.

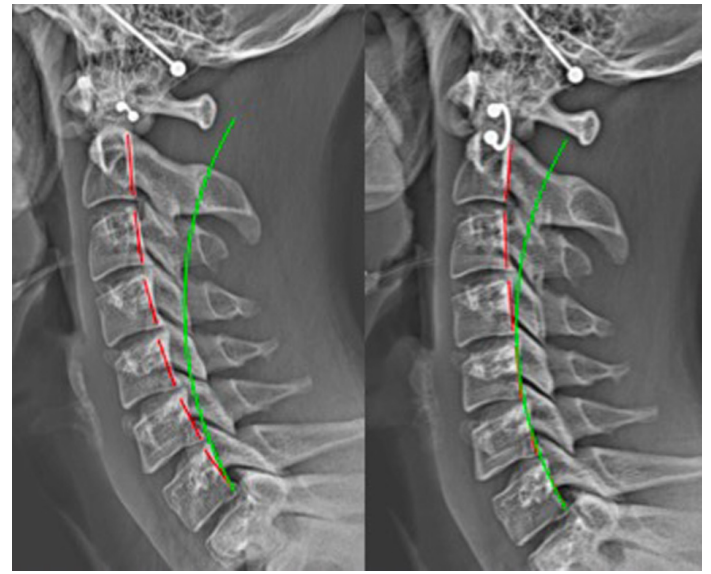

Fig. 2. Lateral cervical views. Left: Initial image showing pronounced forward head position; Right: Reduction of forward head position. Note: patient had ear piercings he refused to remove for X-ray. Red line is patient, green line is ideal alignment.

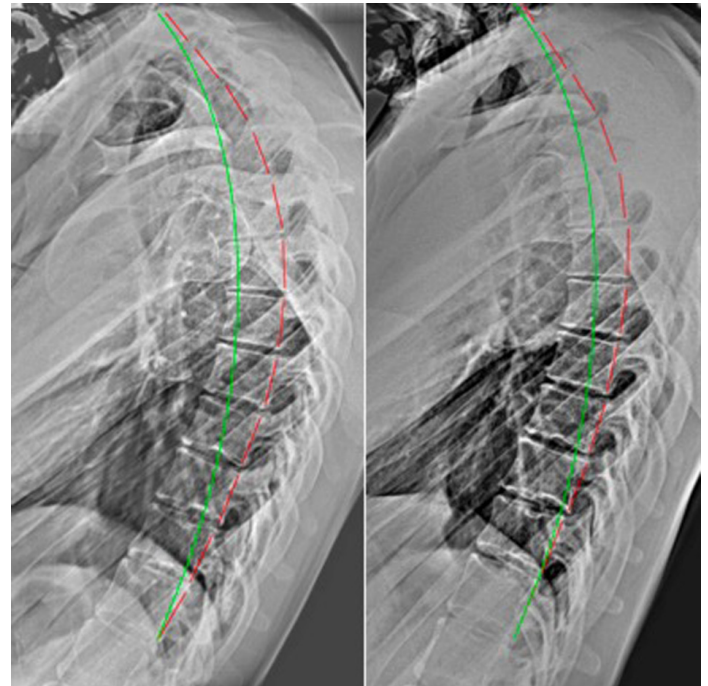

Fig. 3. Lateral thoracic images. Left: Initial image showing exaggerated thoracic hyperkyphosis; Right: Reduction of thoracic kyphosis. Red line is patient, green line is ideal alignment.

\section{DISCUSSION}

This case documents the dramatic improvement in sagittal plane posture in a young male having SD. There was a complete resolution of LBP and headaches and this was accomplished in 14 weeks.

As mentioned, postural deformity subluxation is common, it is causal for pain related complaints ${ }^{3-6)}$, and is associated with a lowered quality of life ${ }^{7}$. Although the incidence of SD is low, in one study only $2 \%$ of 10,057 screened adolescents ${ }^{8)}$, it leads to symptoms decades later ${ }^{31)}$ and those with hyperkyphosis in older ages have serious health detriments from the deformity including increased mortaliy ${ }^{11,32)}$. It is also known that "the earlier the start of treatment, the better the outcome ${ }^{33) \text { " }}$ thus, we agree with Jaeger et al. ${ }^{34)}$ who point out that the early diagnosis of thoracic hyperkyphosis in a younger individual may represent an opportunity to provide correction before the condition has had more time to evolve, and therefore should 


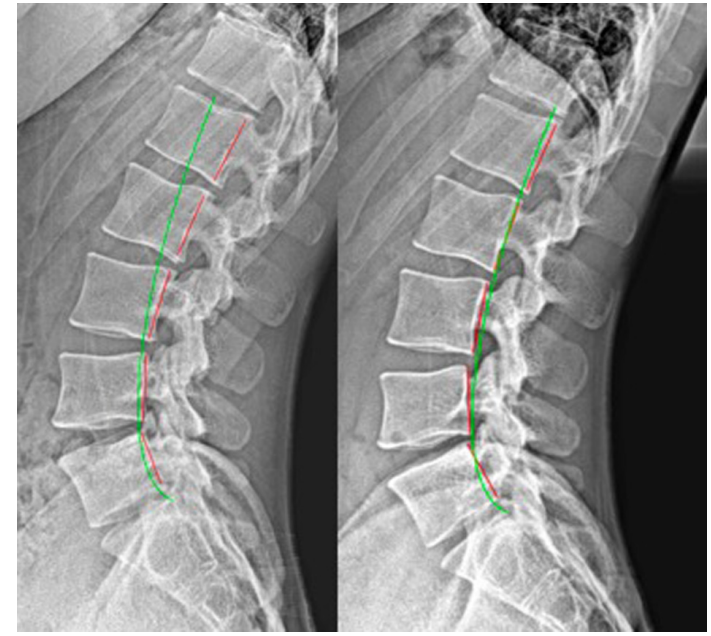

Fig. 4. Lateral lumbar views. Left: Initial image showing posterior translation of the thorax in relation to the pelvis; Right: Correction of the sagittal balance. Red line is patient, green line is ideal alignment.

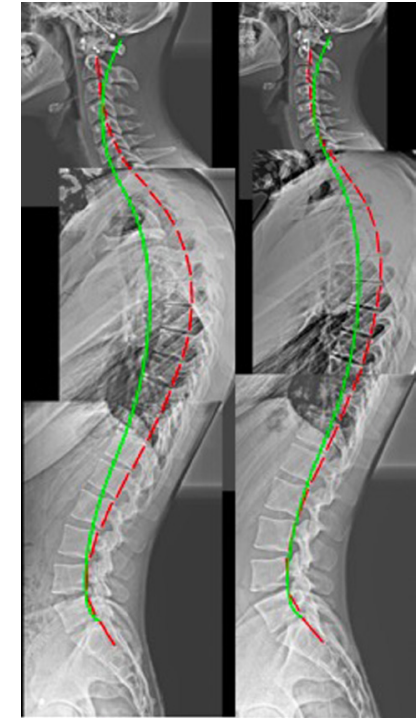

Fig. 5. Whole-spine sagittal view. Red line is patient, green line is ideal alignment.

be treated at the earliest recognition.

Although bracing is a main non-surgical treatment for SD, since it may lead to permanent correction of the deformity (unlike bracing for scoliosis) ${ }^{35}$ ), other effective methods have evolved. The Schroth method has been shown to be effective in reducing the deformity in patients with $\mathrm{SD}^{36,37)}$ and a $9^{\circ}$ reduction has been shown to occur after doing daily exercises for 12 months. It is also noted that in the Bezalel et al. trial, the control group performed anti-gravity exercises daily for 12 months and had a $4^{\circ}$ reduction in kyphosis which is consistent with other exercise trials in thoracic hyperkyphosis in older individuals ${ }^{38,39)}$

In our case, the patient had a $13^{\circ}$ reduction in kyphosis in 14 weeks after 35 treatment sessions. This is consistent with other case reports and case series on CBP technique in reducing thoracic kyphosis as reported in a recent review where it was shown that the average patient with hyperkyphosis experienced a $12^{\circ}$ reduction after 32 treatments over 14 weeks ${ }^{11)}$. It appears that the reduction in thoracic kyphosis by CBP non-surgical methods can result in significant curve reductions that translate into reducing associated symptoms and improving the quality of life in those with thoracic hyperkyphosis including SD. More research into the effectiveness of CBP methods for SD specifically is warranted.

Our patient experienced whole-spine postural improvement, simultaneously occurring with the reduction in thoracic kyphosis. This is important as postural compensation will occur as spinal deformities evolve. Therefore, it is always important to perform full-spine radiographic assessment in patients presenting with spinal deformity (including SD) to properly diagnose biomechanical parameters ${ }^{40}$, as with contemporary methods such as CBP, the treatment will be dictated by the radiographic parameters ${ }^{11)}$.

Limitations to this case are that this is just a single case, however, it is pointed out that the results achieved in reducing the thoracic kyphosis are consistent with other CBP cases and are substantially greater than exercise only trials. A further limitation is that there is no long-term follow-up. A clinical trial is warranted to assess this treatment approach for the correction of poorly hunched posture in the sagittal plane ${ }^{11)}$.

\section{Conflict of interest}

Dr. Paul Oakley (PAO) is a paid consultant for CBP NonProfit, Inc.; Dr. Deed Harrison (DEH) teaches chiropractic rehabilitation methods and sells products to physicians for patient care as used in this manuscript.

\section{REFERENCES}

1) Griegel-Morris P, Larson K, Mueller-Klaus K, et al.: Incidence of common postural abnormalities in the cervical, shoulder, and thoracic regions and their association with pain in two age groups of healthy subjects. Phys Ther, 1992, 72: 425-431. [Medline] [CrossRef]

2) Rusnák R, Kolarová M, Aštaryová I, et al.: Screening and early identification of spinal deformities and posture in 311 children: results from 16 districts in Slovakia. Rehabil Res Pract, 2019, 2019: 4758386. [Medline] [CrossRef]

3) Korovessis PG, Stamatakis MV, Baikousis AG: Reciprocal angulation of vertebral bodies in the sagittal plane in an asymptomatic Greek population. Spine, 
1998, 23: 700-704, discussion 704-705. [Medline] [CrossRef]

4) Jackson RP, McManus AC: Radiographic analysis of sagittal plane alignment and balance in standing volunteers and patients with low back pain matched for age, sex, and size. A prospective controlled clinical study. Spine, 1994, 19: 1611-1618. [Medline] [CrossRef]

5) Protopsaltis TS, Lafage R, Smith JS, et al. International Spine Study Group: The lumbar pelvic angle, the lumbar component of the T1 pelvic angle, correlates with HRQOL, PI-LL mismatch, and it predicts global alignment. Spine, 2018, 43: 681-687. [Medline] [CrossRef]

6) Banno T, Togawa D, Arima H, et al.: The cohort study for the determination of reference values for spinopelvic parameters (T1 pelvic angle and global tilt) in elderly volunteers. Eur Spine J, 2016, 25: 3687-3693. [Medline] [CrossRef]

7) Pellisé F, Vila-Casademunt A, Ferrer M, et al. European Spine Study Group, ESSG: Impact on health related quality of life of adult spinal deformity (ASD) compared with other chronic conditions. Eur Spine J, 2015, 24: 3-11. [Medline] [CrossRef]

8) Fotiadis E, Kenanidis E, Samoladas E, et al.: Scheuermann's disease: focus on weight and height role. Eur Spine J, 2008, 17: 673-678. [Medline] [CrossRef]

9) Bezalel T, Carmeli E, Been E, et al.: Scheuermann's disease: current diagnosis and treatment approach. J Back Musculoskeletal Rehabil, 2014, 27: 383-390. [Medline] [CrossRef]

10) Ali RM, Green DW, Patel TC: Scheuermann's kyphosis. Curr Opin Pediatr, 1999, 11: 70-75. [Medline] [CrossRef]

11) Oakley PA, Harrison DE: Reducing thoracic hyperkyphosis subluxation deformity: a systematic review of chiropractic BioPhysics ${ }^{\circledR}$ methods employed in its structural improvement. J Contemp Chiropr, 2018, 1: 59-66.

12) Fairbank JC, Couper J, Davies JB, et al.: The Oswestry low back pain disability questionnaire. Physiotherapy, 1980, 66: 271-273. [Medline]

13) Harrison DE, Harrison DD, Cailliet R, et al.: Cobb method or Harrison posterior tangent method: which to choose for lateral cervical radiographic analysis. Spine, 2000, 25: 2072-2078. [Medline] [CrossRef]

14) Harrison DE, Cailliet R, Harrison DD, et al.: Reliability of centroid, Cobb, and Harrison posterior tangent methods: which to choose for analysis of thoracic kyphosis. Spine, 2001, 26: E227-E234. [Medline] [CrossRef]

15) Harrison DE, Harrison DD, Cailliet R, et al.: Radiographic analysis of lumbar lordosis: centroid, Cobb, TRALL, and Harrison posterior tangent methods. Spine, 2001, 26: E235-E242. [Medline] [CrossRef]

16) Harrison DE, Holland B, Harrison DD, et al.: Further reliability analysis of the Harrison radiographic line-drawing methods: crossed ICCs for lateral posterior tangents and modified Risser-Ferguson method on AP views. J Manipulative Physiol Ther, 2002, 25: 93-98. [Medline] [CrossRef]

17) Harrison DE, Harrison DD, Colloca CJ, et al.: Repeatability over time of posture, radiograph positioning, and radiograph line drawing: an analysis of six control groups. J Manipulative Physiol Ther, 2003, 26: 87-98. [Medline] [CrossRef]

18) Harrison DE, Oakley PA: Necessity for biomechanical evaluation of posture, alignment and subluxation. Part I: The 6 subluxation types that satisfy Nelson's criteria for valid subluxation theory. J Contemp Chiropr, 2018, 1: 9-19.

19) Harrison DD, Janik TJ, Troyanovich SJ, et al.: Comparisons of lordotic cervical spine curvatures to a theoretical ideal model of the static sagittal cervical spine. Spine, 1996, 21: 667-675. [Medline] [CrossRef]

20) Harrison DD, Harrison DE, Janik TJ, et al.: Modeling of the sagittal cervical spine as a method to discriminate hypolordosis: results of elliptical and circular modeling in 72 asymptomatic subjects, 52 acute neck pain subjects, and 70 chronic neck pain subjects. Spine, 2004, 29: 2485-2492. [Medline] [CrossRef]

21) Harrison DE, Colloca CJ, Harrison DD, et al.: Anterior thoracic posture increases thoracolumbar disc loading. Eur Spine J, 2005, 14: 234-242. [Medline] [CrossRef]

22) Harrison DE, Janik TJ, Harrison DD, et al.: Can the thoracic kyphosis be modeled with a simple geometric shape? The results of circular and elliptical modeling in 80 asymptomatic patients. J Spinal Disord Tech, 2002, 15: 213-220. [Medline] [CrossRef]

23) Harrison DD, Cailliet R, Janik TJ, et al.: Elliptical modeling of the sagittal lumbar lordosis and segmental rotation angles as a method to discriminate between normal and low back pain subjects. J Spinal Disord, 1998, 11: 430-439. [Medline] [CrossRef]

24) Janik TJ, Harrison DD, Cailliet R, et al.: Can the sagittal lumbar curvature be closely approximated by an ellipse? J Orthop Res, 1998, 16: 766-770. [Medline] [CrossRef]

25) McAviney J, Schulz D, Bock R, et al.: Determining the relationship between cervical lordosis and neck complaints. J Manipulative Physiol Ther, 2005, 28: 187-193. [Medline] [CrossRef]

26) Legaye J, Duval-Beaupère G, Hecquet J, et al.: Pelvic incidence: a fundamental pelvic parameter for three-dimensional regulation of spinal sagittal curves. Eur Spine J, 1998, 7: 99-103. [Medline] [CrossRef]

27) Legaye J: The femoro-sacral posterior angle: an anatomical sagittal pelvic parameter usable with dome-shaped sacrum. Eur Spine J, 2007, 16: 219-225. [Medline] [CrossRef]

28) Harrison DD, Janik TJ, Harrison GR, et al.: Chiropractic biophysics technique: a linear algebra approach to posture in chiropractic. J Manipulative Physiol Ther, 1996, 19: 525-535. [Medline]

29) Oakley PA, Harrison DD, Harrison DE, et al.: Evidence-based protocol for structural rehabilitation of the spine and posture: review of clinical biomechanics of posture (CBP) publications. J Can Chiropr Assoc, 2005, 49: 270-296. [Medline]

30) Lee DY: Analysis of muscle activation in each body segment in response to the stimulation intensity of whole-body vibration. J Phys Ther Sci, 2017, 29: 270-273. [Medline] [CrossRef]

31) Ristolainen L, Kettunen JA, Heliövaara M, et al.: Untreated Scheuermann's disease: a 37-year follow-up study. Eur Spine J, 2012, 21: 819-824. [Medline] [CrossRef]

32) Roghani T, Zavieh MK, Manshadi FD, et al.: Age-related hyperkyphosis: update of its potential causes and clinical impacts-narrative review. Aging Clin Exp Res, 2017, 29: 567-577. [Medline] [CrossRef]

33) Palazzo C, Sailhan F, Revel M: Scheuermann's disease: an update. Joint Bone Spine, 2014, 81: 209-214. [Medline] [CrossRef]

34) Jaeger JO, Oakley PA, Colloca CJ, et al.: Non-surgical reduction of thoracic hyper-kyphosis in a 24-year old music teacher utilizing chiropractic BioPhysics ${ }^{\circledR}$ technique. Br J Med Med Res, 2016, 11: 1-9. [CrossRef]

35) Pizzutillo PD: Nonsurgical treatment of kyphosis. Instr Course Lect, 2004, 53: 485-491. [Medline]

36) Weiss HR, Dieckmann J, Gerner HJ: Effect of intensive rehabilitation on pain in patients with Scheuermann's disease. Stud Health Technol Inform, 2002, 88: 254-257. [Medline] 
37) Bezalel T, Carmeli E, Levi D, et al.: The effect of Schroth therapy on thoracic kyphotic curve and quality of life in Scheuermann's patients: a randomized controlled trial. Asian Spine J, 2019, 13: 490-499. [CrossRef]. [Medline]

38) Itoi E, Sinaki M: Effect of back-strengthening exercise on posture in healthy women 49 to 65 years of age. Mayo Clin Proc, 1994, 69: 1054-1059. [Medline] [CrossRef]

39) Katzman WB, Vittinghoff E, Lin F, et al.: Targeted spine strengthening exercise and posture training program to reduce hyperkyphosis in older adults: results from the study of hyperkyphosis, exercise, and function (SHEAF) randomized controlled trial. Osteoporos Int, 2017, 28: 2831-2841. [Medline] [CrossRef]

40) Bess S, Protopsaltis TS, Lafage V, et al. International Spine Study Group: Clinical and radiographic evaluation of adult spinal deformity. Clin Spine Surg, 2016, 29: 6-16. [Medline] [CrossRef] 